LA-UR-01-5211

Approved for public release;

distribution is unlimited.

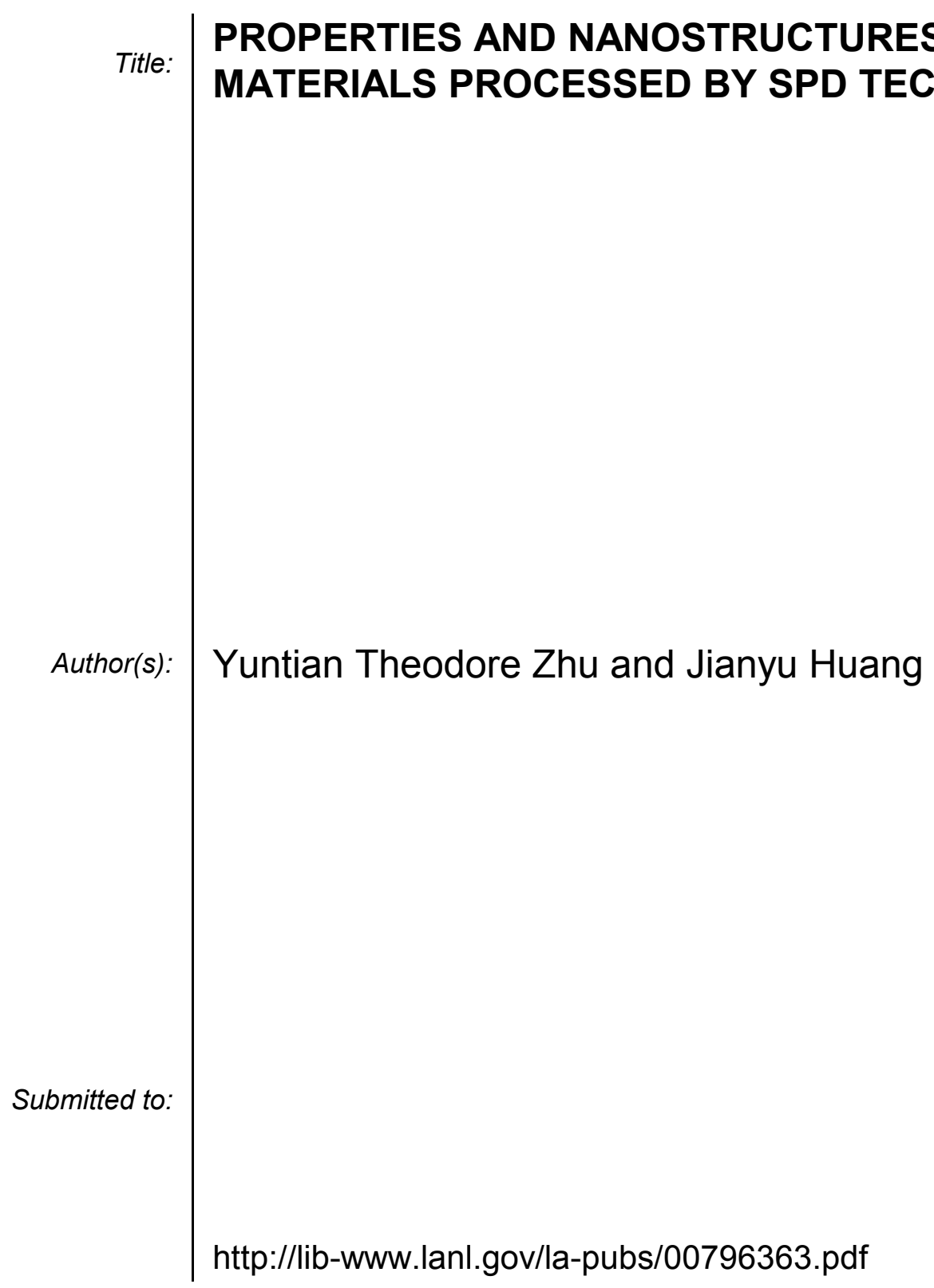

Los Alamos National Laboratory, an affirmative action/equal opportunity employer, is operated by the University of California for the U.S. Department of Energy under contract W-7405-ENG-36. By acceptance of this article, the publisher recognizes that the U.S. Government retains a nonexclusive, royaltyfree license to publish or reproduce the published form of this contribution, or to allow others to do so, for U.S. Government purposes. Los Alamos National Laboratory requests that the publisher identify this article as work performed under the auspices of the U.S. Department of Energy. Los Alamos National Laboratory strongly supports academic freedom and a researcher's right to publish; as an institution, however, the Laboratory does not endorse the viewpoint of a publication or guarantee its technical correctness. 


\title{
PROPERTIES AND NANOSTRUCTURES OF MATERIALS PROCESSED BY SPD TECHNIQUES
}

\author{
Yuntian Theodore Zhu and Jianyu Huang \\ MS G755, Materials Science and Technology Division \\ Los Alamos National Laboratory, Los Alamos, NM 87545
}

\begin{abstract}
Metallic materials usually exhibit higher strength but lower ductility after being plastically deformed by conventional techniques such as rolling, drawing and extrusion. In contrast, nanostructured metals and alloys processed by severe plastic deformation (SPD) have demonstrated both high strength and high ductility. This extraordinary mechanical behavior is attributed to the unique nanostructures generated by SPD processing. It demonstrates the possibility of tailoring the microstructures of metals and alloys by SPD to obtain superior mechanical properties. The SPD-generated nanostructures have many features related to deformation, including high dislocation densities, and high- and low-angle grain boundaries in equilibrium or non-equilibrium states. This paper reviews the mechanical properties and the defect structures of SPD-processed nanostructured materials.
\end{abstract}

Keywords: strength, ductility, nanostructures, SPD, non-equilibrium grain boundary

\section{Introduction}

Two complementary approaches have been developed to synthesize nanostructured materials. The first one is a "bottom-up" approach, in which bulk nanostructured materials are assembled from individual atoms or nanoscale building blocks such as nano-particles [1]. Gleiter's pioneering work [2] is a typical example of the "bottom-up" approach. Various chemical and physical methods have been developed to synthesize nano-powders for smallscale laboratory investigations as well as for large-scale commercial use. Ceramic and metallic nano-powders can now be readily purchased from an increasing number of nano-technology companies. However, consolidation of nano-particles into bulk nanostructured materials has been largely unsuccessful. Gleiter [2] and Nieman et al [3] cold-compacted inert-gascondensation (IGC)-produced nano-powders in situ in ultrahigh vacuum and obtained nanostructured discs typically a few hundred micrometers in thickness and less than $10 \mathrm{~mm}$ in diameter. The as-produced samples contained many flaws that mask the intrinsic mechanical properties [4]. Such flaws include gas-filled pores, cracks, poorly bonded grains, etc. These flaws render the material brittle, especially under tensile state of stress. More recently, Sanders et al [5] used warm compaction to reduce the density and size of such flaws and found improvement in the mechanical properties. However, flaws such as porosity and trapped gas

Ultrafine Grained Materials II; Edited by Y.T. Zhu, T.G. Langdon, R.S. Mishra, S.L. Semiatin, M.J. Saran, and T.C. Lowe. TMS (The Minerals, Metals \& Materials Society), 2002. 
still exist in the consolidated nanomaterials. A series of other conventional and new techniques, such as hot pressing, hot isostatic pressing (HIP) [6], rapid hot forging [7, 8] and plasma activated sintering (PAS) [9], have been used to consolidate nano-powders. Most of these techniques involve the applications of heat and pressure. Grain growth usually occurs during the consolidation, although nanopowder oxidation and contaminants may help impede grain growth.

The second approach for producing nanostructured materials is a "top-down" approach, in which existing materials are refined into nanostructured materials. The most successful "topdown" approach has been via severe plastic deformation (SPD) techniques, among which the most developed are equal channel angular pressing (ECAP) and high pressure torsion (HPT) [10]. HPT can only produce small disc-shaped samples. The ECAP technique was first invented by Segal in 1972 [11], and was later used to produce nanostructured materials [12]. Recently, new SPD techniques have been developed, such as multipass-coin-forge (MCF) [13], multi-axis deformation [14], and repetitive corrugation and straightening (RCS) [15]. Note that the RCS process has the potential to scale up for large-scale industrial production. The RCS process (see Fig. 1) involves the repeated rolling and straightening of the work-piece through system of gear-like rollers, as depicted in Fig. 1. Similar to the ECAP, the RCS introduces large amount of plastic deformation to the work-piece without significantly changing its cross-sectional geometry. This allows the work-piece to be processed repetitively to refine its grain size without reducing the work-piece to the

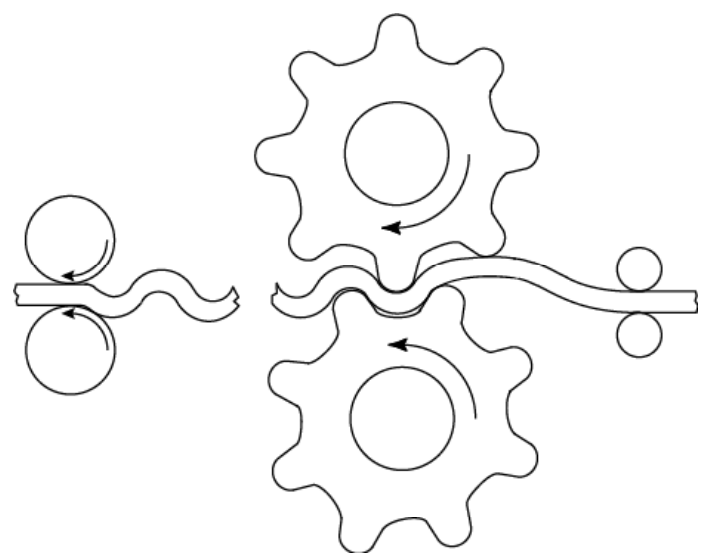

Fig. 1. A process cycle for continuous RCS. geometry of foil or wire.

SPD-produced materials such as $\mathrm{Cu}, \mathrm{Fe}$ and Ti typically have an average grain size of 100$200 \mathrm{~nm}$ [10], somewhat above $100 \mathrm{~nm}$, the upper bound often used to define the nanostructured materials. However, subgrains with low misorientation angles, dislocation cell structures [15], and the coherent crystallite domains as measured by X-ray analysis are usually smaller than $100 \mathrm{~nm}$. Therefore, materials produced by SPD can be indeed classified as nanostructured materials.

This paper discusses the unique mechanical properties and nanostructures of nanostructured materials produced by SPD methods.

\section{Mechanical Properties}

It is well known that plastic deformation induced by conventional forming methods such as rolling, drawing or extrusion can significantly increase the strength of metals [16,17]. However, this increase is usually accompanied by a loss of ductility. For example, as shown in Fig. 2, with increasing rolling strain, the yield strengths of $\mathrm{Al}, \mathrm{Cu}$ and $\mathrm{Cu}-0.32 \mathrm{Ag}$ alloy monotonically increase, accompanied by a monotonic decrease in ductility (elongation to failure). The same trend is also true for other metals and alloys. Note that for heavily rolled metals, the ductility could slightly increase with increasing rolling strain. However, this increase is very limited and the overall ductility is usually very low. For example, elongation to failure of pure $\mathrm{Ni}$ and $\mathrm{Al}$ increased from $1.2 \%$ to $4 \%$ and from $6 \%$ to $8 \%$, respectively, when the rolling strain increased from 4 to 6 for $\mathrm{Ni}$ and 2 to 4 for $\mathrm{Al}$ [18]. 
In contrast, nanostructured metals and alloys processed by SPD techniques such as ECAP and HPT have demonstrated high strength, while retaining high ductility. Horita et al [19] compared the strength and ductility of 3004 aluminum alloy processed by ECAP and cold rolling. As shown in Fig. 3, for both cold-rolled and ECAPed 3004 alloy, the yield strength increased monotonically with increasing equivalent strain imparted into the alloy by cold rolling or ECAP. However, the ductility of the alloy demonstrated different trends for the two different processing methods. Note that in Fig. 3, each ECAP pass imparts an equivalent strain of 1. After one ECAP pass (a strain of 1 ), the elongation to failure (ductility) of the 3004 alloy decreased from $32 \%$ to about $14 \%$. Further ECAP passes (or larger ECAP strains) did not decrease the ductility further. In contrast, the cold rolling decreased the ductility of the 3004 alloy in a similar magnitude initially, but the ductility continue to decrease with increasing rolling strain, although the decrease slows down. This demonstrates that the deformation mode (or strain path) has a significant effect on the ductility of the metals. Cold rolling introduces plastic strain into the work-piece with one deformation mode (strain path), while ECAP changes the strain path by rotating the work-piece $90^{\circ}$ clockwise between two adjacent passes (ECAP route $\mathrm{B}_{\mathrm{C}}$ ) $[19,20]$. Consequently, the ECAP processing resulted in equiaxed grains, in contrast to the elongated grains typically produced by cold rolling. The different microstructure as well as texture rendered remarkably different ductilities. The high ductility of the ECAP processed metals is highly desired for structural applications.

Recently, even higher ductility was found in copper and titanium processed by ECAP and HPT to a higher strain [21]. The pure $\mathrm{Cu}(99.996 \%)$ was processed using ECAP with $90^{\circ}$ clockwise rotations along the billet axis between consecutive passes. All

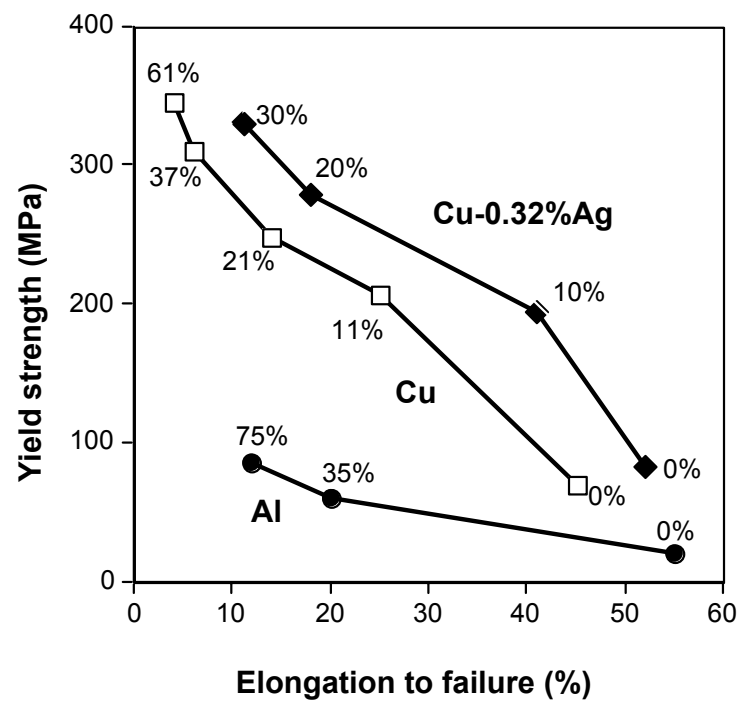

Fig. 2. With increasing rolling strain, the yield strengths of $\mathrm{Al}, \mathrm{Cu}$ and a $\mathrm{Cu}$ alloy increase but their ductilities decrease.
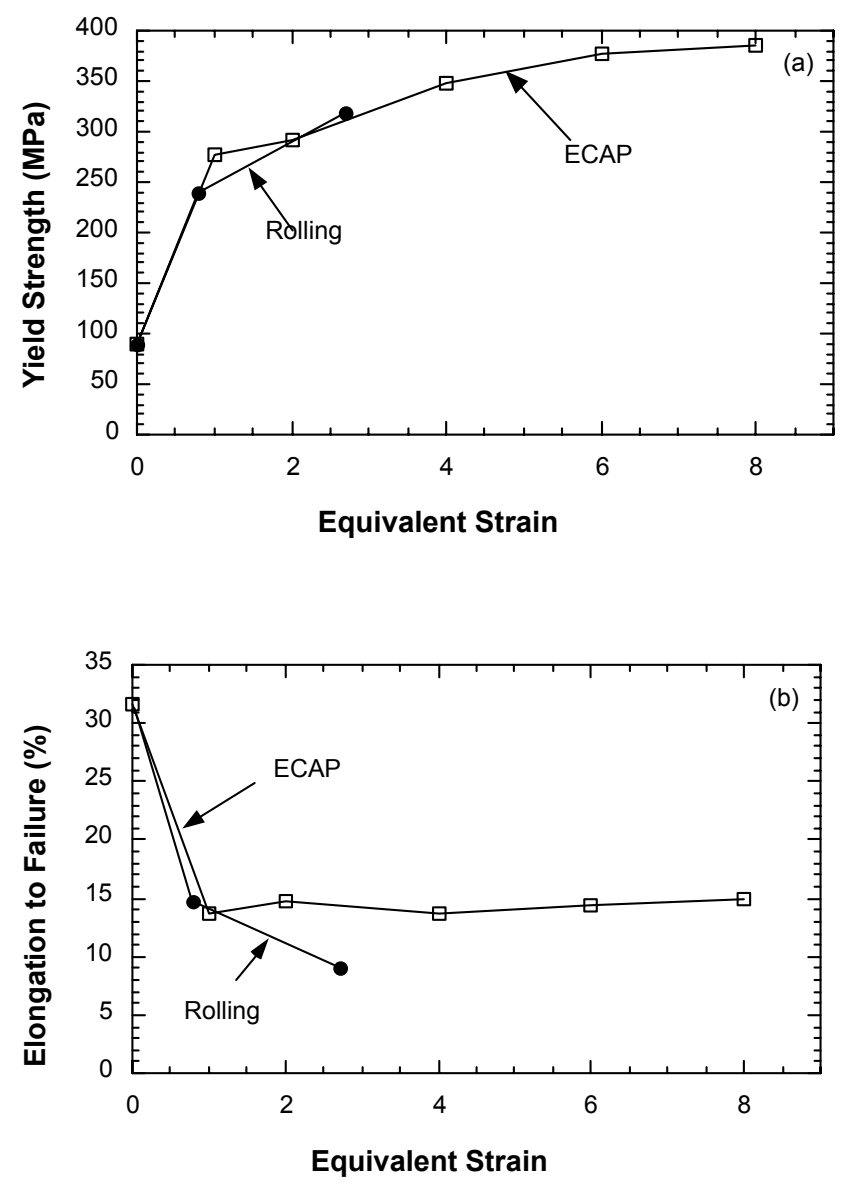

Fig. 3. Comparison of yield strength and ductility of the $3004 \mathrm{Al}$ alloy processed by cold rolling and ECAP [18]. 
processes were performed at room temperature. Results for $\mathrm{Cu}$ tested at room temperature in its initial and three processed states are shown in Fig. 4. The initial coarse-grained $\mathrm{Cu}$, with a grain size of about $30 \mu \mathrm{m}$, has a low yield stress but exhibits significant strain hardening and a large elongation to failure. This behaviour is typical of coarsegrained metals. The elongation to failure is a quantitative measure of ductility, and is taken as the engineering strain at which the sample broke. Cold rolling of the copper to a thickness reduction of $60 \%$ significantly increased the strength (curve 2), but dramatically decreased the elongation to failure. This is consistent with the classical

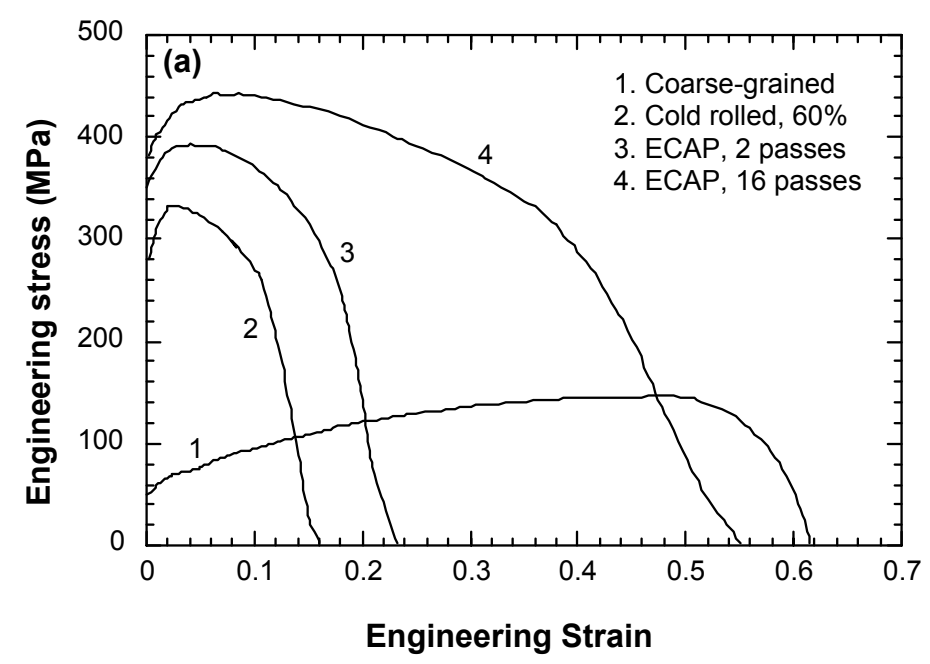

Fig. 4. Tensile engineering stress-strain curves of a) $\mathrm{Cu}$ tested at $22^{\circ} \mathrm{C}$ and b) Ti tested at $250^{\circ} \mathrm{C}$. Both were tested at a strain rate of $10^{-3} \mathrm{~s}^{-1}$. The processing conditions for each curve are listed on the figure.

mechanical behaviour of metals that are deformed plastically [22,23]. This tendency is also true for $\mathrm{Cu}$ subjected to two passes of ECAP (curve 3). However, further deforming the $\mathrm{Cu}$ to 16 ECAP passes simultaneously increased both the strength and ductility (curve 4). Furthermore, the increase in ductility is much more significant than the increase in strength. Such results have never been observed before and challenge our current understanding of mechanical properties of metals processed by plastic deformation. Similar results were also observed in Ti samples subjected to HPT, which were tested in tension at $250^{\circ} \mathrm{C} \mathrm{[21].}$

These results are contrary to the classical mechanical behaviour of metals that are deformed plastically. Greater plastic deformation by conventional techniques such as rolling, drawing or extrusion introduces greater strain hardening, which in turn increases the strength, but decreases the ductility of the metal. The extraordinary mechanical behaviour in metals processed by SPD suggests a fundamental change in deformation mechanisms after the metals have been processed by SPD to very large strains. It also suggests the possibility of tailoring the microstructures through SPD to obtain superior mechanical properties.

\section{Nanostructures}

Nanostructured materials synthesized by SPD techniques have unique nanostructures. The grain size distribution usually follows a lognormal statistical function [24]. ECAP, especially route $\mathrm{B}_{\mathrm{C}}$, in which the work-piece is rotated $90^{\circ}$ clockwise between adjacent passes, can produce equiaxed grains (see Fig. 5). In small grains, very few lattice dislocations are observed; in grains of intermediate size, a high-density of lattice dislocations exist; in large grains, subgrains are observed [10]. The nanostructures of metals and alloys processed by ECAP and HPT techniques have been reported by many research groups [10, 25-27]. In the following, the nanostructures and crystalline defects in a copper processed by RCS will be presented.

A pure $\mathrm{Cu}$ bar was processed by discontinuous RCS (see the setup shown in Fig. 6) [15]. The average grain size of the copper before RCS processing is $760 \mu \mathrm{m}$. A basic RCS cycle consists of two steps: corrugation and straightening. The first step was carried out by 


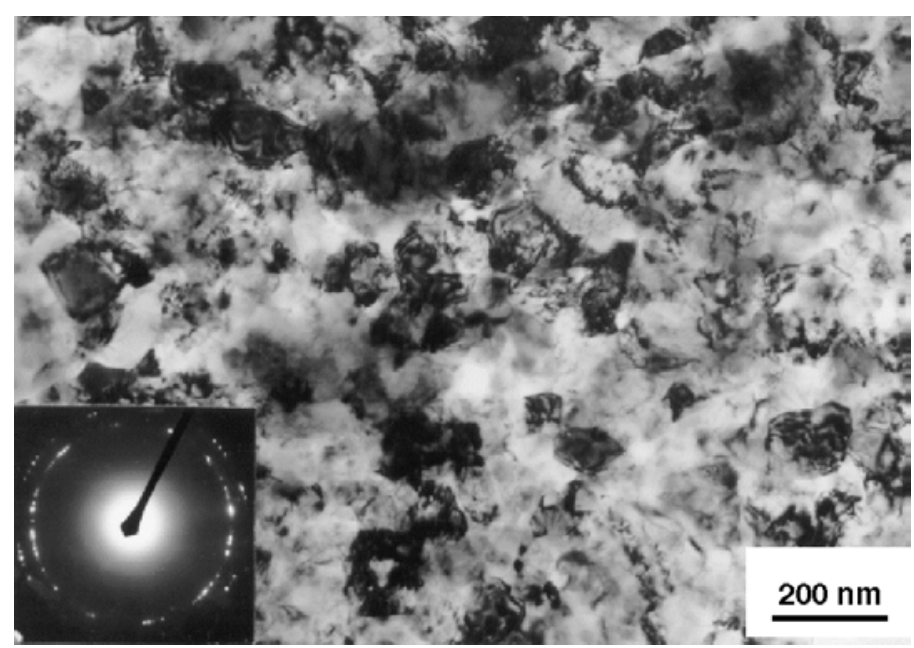

Fig. 5. TEM micrographs of $\mathrm{Cu}$ after ECAP for 16 passes (Valiev et al 2000b).

copper bar was immersed in liquid nitrogen for 3 minutes before each RCS cycle. The RCS cycle was repeated 14 times with $90^{\circ}$ rotations between consecutive cycles.

The nanostructure of the RCS-processed copper observed under TEM is shown in Fig. 7. It is seen that the grain size ranges from twenty to a few hundred nanometers. Most of the crystallites are separated by low-angle grain boundaries that consist of dislocation arrays, as pointed out by the black arrowheads. Boundaries separating grains with a misorientation less than $15^{\circ}$ are defined as low-angle grain boundaries. High-angle grain boundaries also exist in many places, as marked by long white arrows. Because of the large initial grain size (760 $\mu \mathrm{m})$, the whole area shown in Fig. 7 should be from one single initial grain. In other words, the microstructure shown in Fig. 7 was produced from a single copper crystal by the RCS process. The orientations of the nano-grains shown in Fig. 7 spread as wide as $55^{\circ}$ [15]. Figure 7 also shows high dislocation densities in most of the new grains. In some deforming the work-piece to a corrugated shape (Fig. 6), and the second step was accomplished by straightening the corrugated work-piece between two flat platens. The

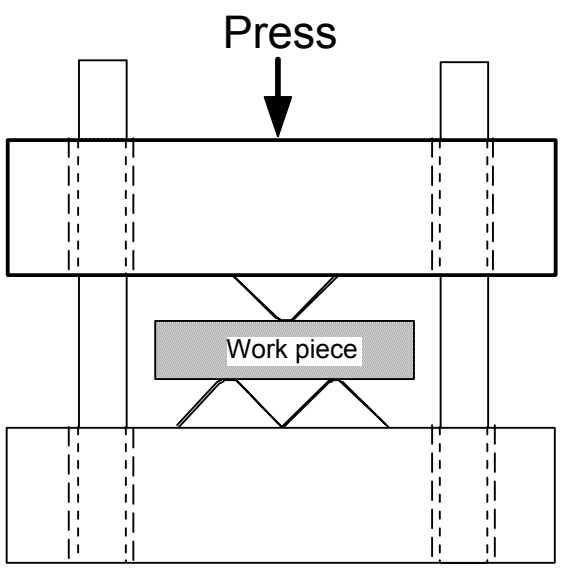

Fig. 6. A discontinuous RCS setup.

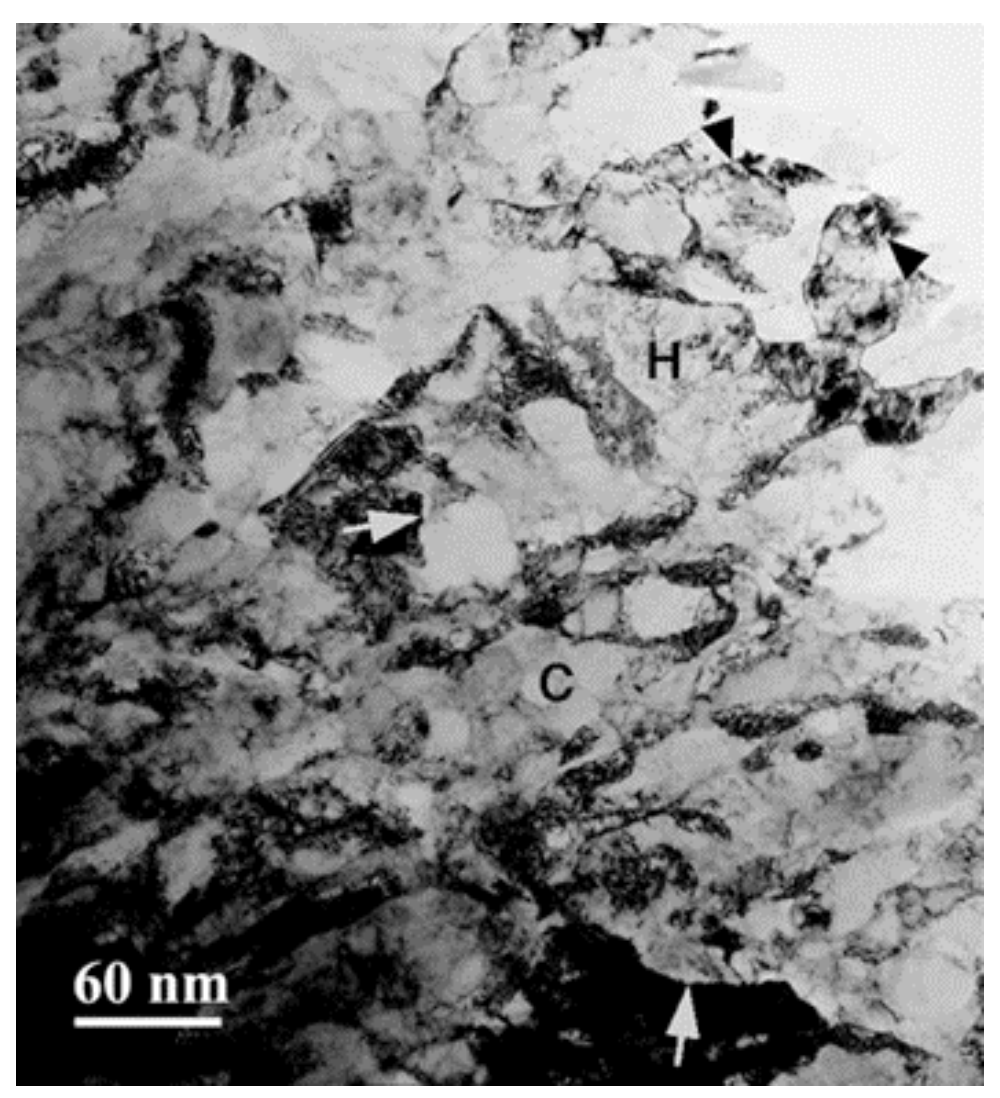

Fig. 7. TEM micrograph shows nanostructures in copper processed by RCS. 
of the larger grains, the distribution of dislocations are fairly homogeneous in the grain interior (see the grain marked $\mathrm{H}$ ), while in other large grains dislocations form cell walls (see the grain marked C).

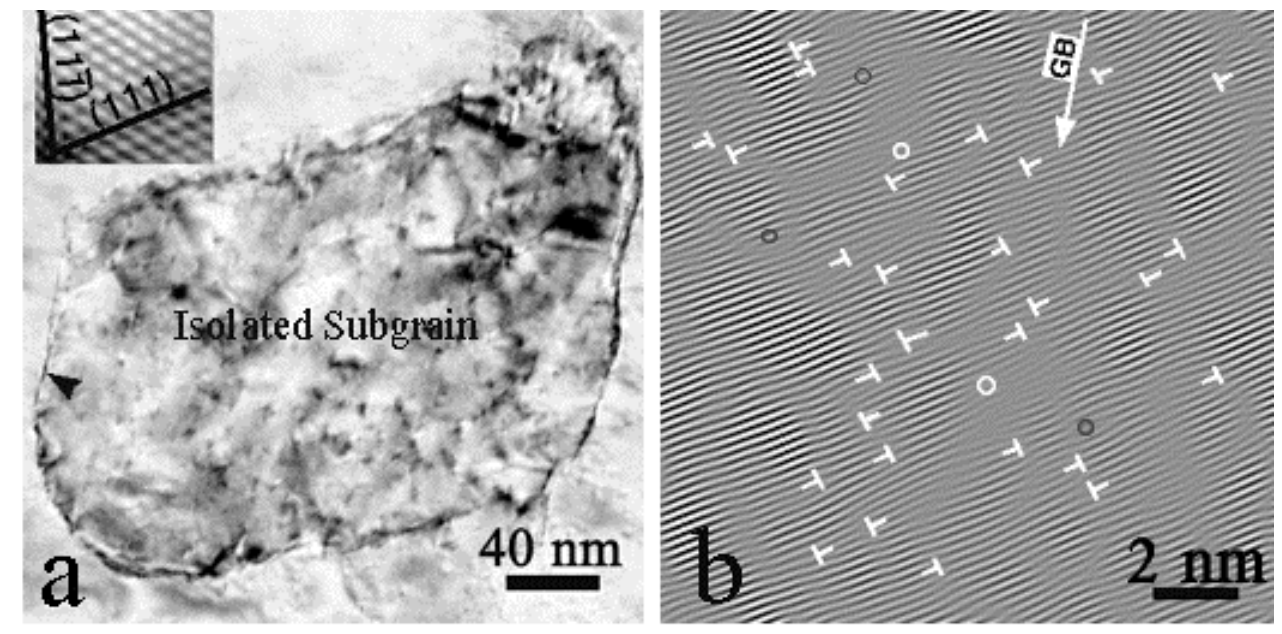

Fig. 8. (a) A TEM micrograph of a subgrain; (b) An HRTEM image from the DDW as pointed out by an arrowhead in (a). The dislocations are glissile type. The longer arrow points out the grain boundary orientation. The black and white circles mark interstitial vacancy loops, respectively.

Subgrains exist in RCS-processed nanostructured copper [28]. As shown in Fig. 8a, dense dislocation walls (DDWs) [29], which are almost parallel to the two sets of $\{111\}$ planes, delineate a subgrain with a size of about $250 \mathrm{~nm}$. High-density dislocations exist inside the subgrain and are forming cell structures. Figure $8 \mathrm{~b}$ is a high resolution TEM (HRTEM) image of the DDW subgrain boundary at the point marked by an arrowhead in Fig. 8a. The dislocation density is estimated as $3 \times 10^{17}$ $\mathrm{m}^{-2}$ at the DDW. Interstitial loops (marked by black circles) and vacancy loops (marked by white circles) also exist. The dislocations are mostly glissile type. In addition, the lattice planes near the cell walls are heavily distorted. The misorientation across the subgrain

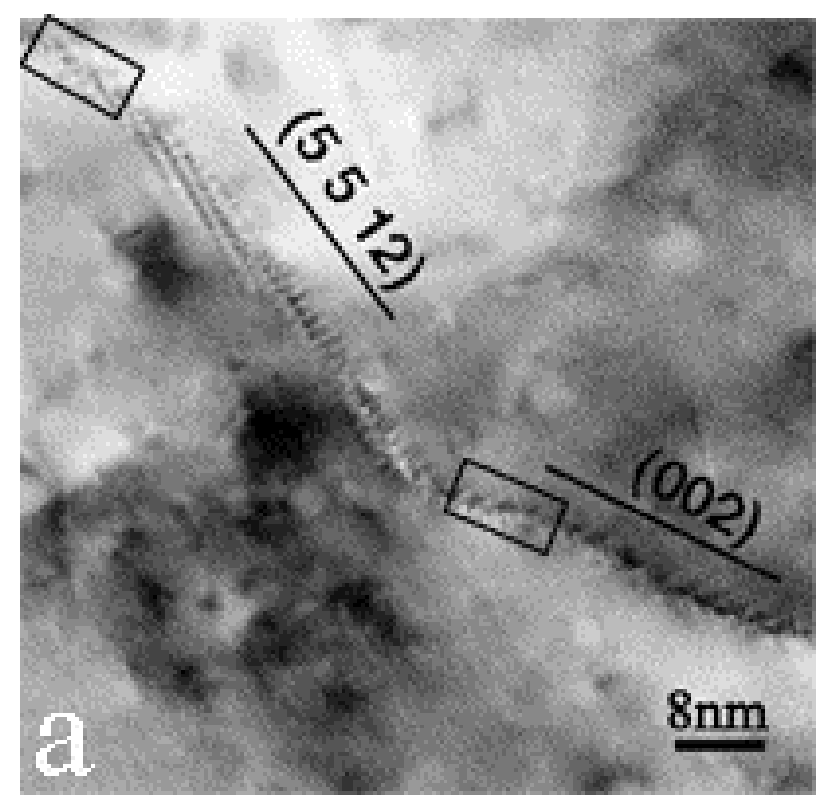

Fig. 9. A TEM micrograph of a low-angle GB. boundary is measured as about $5^{\circ}$. There are significantly more dislocations than required to accommodate the misorientation. Thus, this subgrain boundary is in a non-equilibrium state.

Both equilibrium and non-equilibrium grain boundaries (GBs) exist in nano-structured materials synthesized by SPD. Shown in Fig. 9 is a low-angle GB with a misorientation of $9^{\circ}$ in RCS-processed $\mathrm{Cu}$ [28]. An HRTEM image from the upper-left frame in Fig. 9 is shown in Fig. 10a. Figure 10b is a structural model for the low-angle GB in Fig. 10a. It is seen from Fig. $10 \mathrm{~b}$ that two types of dislocations, marked with $\mathbf{T}$ and $\tau$ respectively, are needed to accommodate the geometrical misorientation. In other words, these are geometrically 

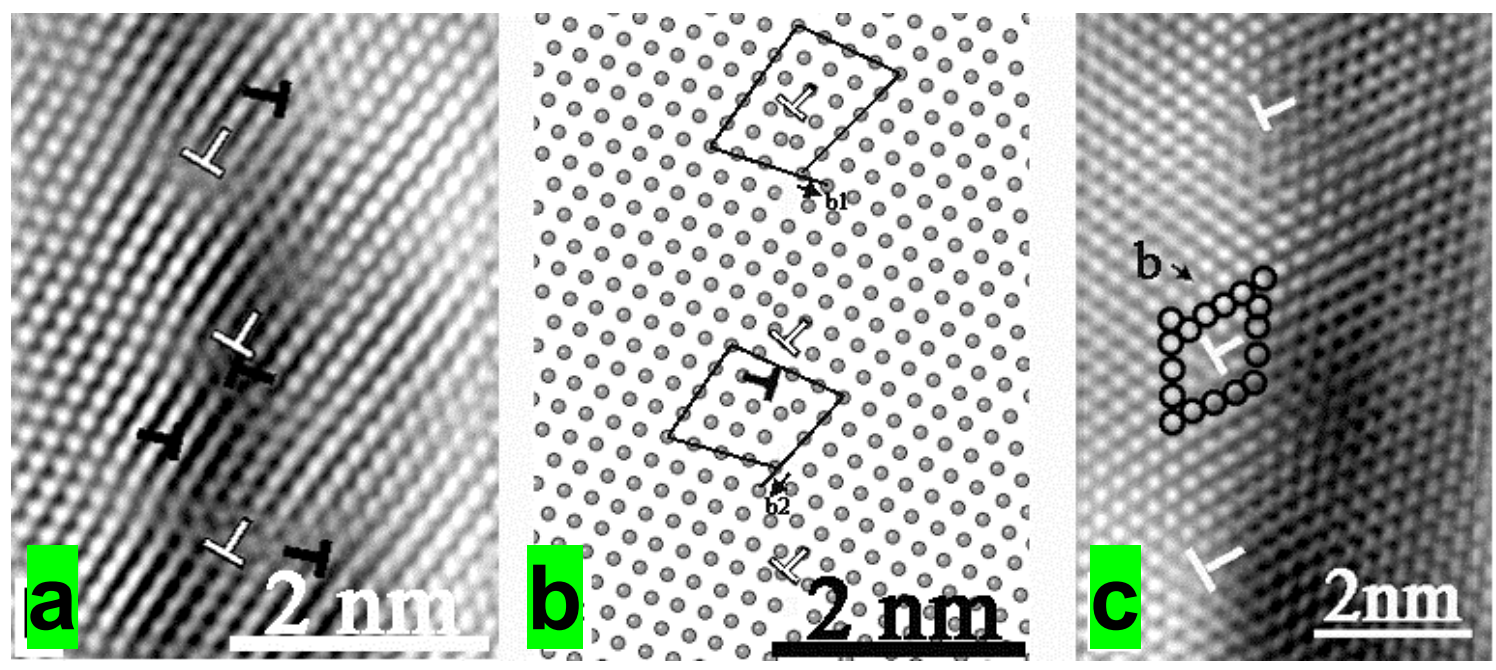

Fig. 10. (a) and (b) an HRTEM image and a structural model of the GB in the upper-left frame in Fig. 9; (c) an HRTEM image of the GB in the lower-right frame.

necessary, or intrinsic, dislocations [10]. Fig. 10a clearly shows three more T-type dislocations than Fig. 10b, which indicates that three extrinsic (or non-geometrically-necessary) dislocations exist at the GB shown in Fig. 10a. Therefore, this segment of low-angle GB is in a high-energy configuration and should be called non-equilibrium GB. On the other hand, Fig. $10 \mathrm{c}$ shows that the GB in the lower-right frame is in an equilibrium state with no extrinsic dislocations.

Non-equilibrium GBs were also observed in ECAP-processed Al-Mg and Al-Mg-Sc alloys [30], HPT-processed Al-Mg alloys, high purity $\mathrm{Cu}$ and $\mathrm{Ni}[31,32]$, and an HPT-processed NiAl-Cr alloy [33]. These works concluded that the grain boundaries were in non-equilibrium, high energy states because they were curved and there were "gradual changes in the boundary inclinations within the foil" [30]. Dislocations were also observed on the grain boundaries although no attempt was made to see if there was any extrinsic dislocation.

Figure 11 shows a TEM micrograph of a grain with a diameter of about $500 \mathrm{~nm}$ in RCSprocessed $\mathrm{Cu}$ [28]. A number of fine structures were observed in the interior of the grain. As pointed out by two arrowheads, an array of dislocations piled up along the (111) plane. Consequently, two subgrains (denoted by 1 and 2) with a misorientation of about $1^{\circ}$ were produced (measured from the HRTEM image, not shown here). The dislocations are mostly $60^{\circ}$ type and are glissible along the $\{111\}$ planes. A low-angle GB was also found in this grain, as marked by four stars. The low-angle GB was formed by the accumulation of a number of glissile dislocations. It is not edge-on but overlapped, as revealed by the periodic Moiré Fringes. The misorientation of the two grains as measured from an HREM image is about $5^{\circ}$.

Dislocation cell structure was also observed in subgrain 3 in Fig. 11. These cells may form individual subgrains upon further plastic straining. Dislocation tangling was frequently observed in the interior of grains, as marked by a white circle, where the grain is heavily strained. Such a region was referred to as dislocation-tangle zone (DTZ). In the area marked by a white square, dislocation cells are forming from tangled dislocations. 


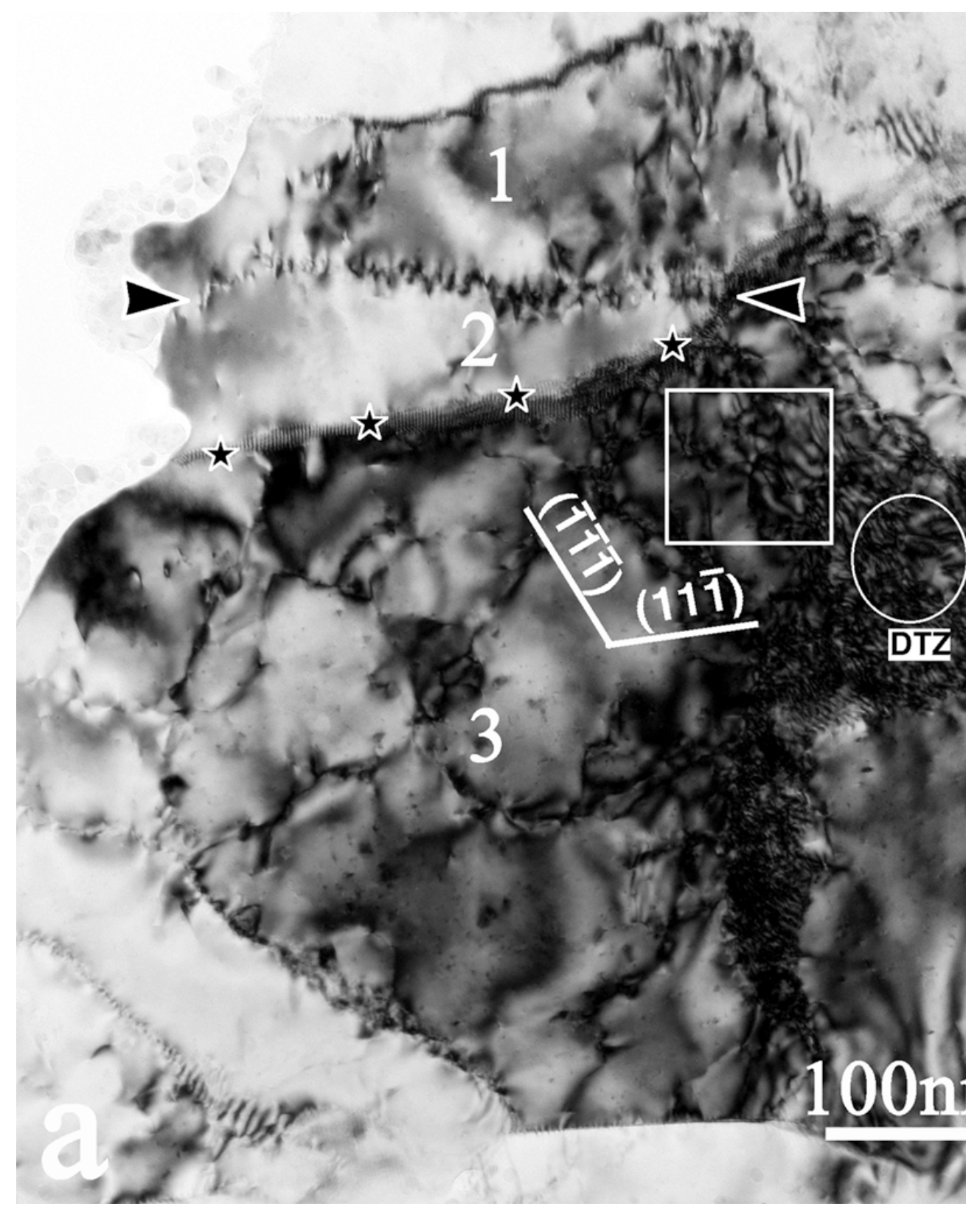

Fig. 11. A TEM micrograph showing fine deformation structures in a grain. The numbers 1, 2 and 3 denote three subgrains; the two arrowheads point out an array of dislocations; the four stars mark a low-angle GB; the white circle marks a dislocation tangle zone (DTZ); the white square marks a transition from DTZ to dislocation cells.

\section{Conclusions}

Nanostructured metals and alloys processed by SPD techniques have significantly higher strength than their coarse-grained counterparts while retaining relatively high ductility. It is possible to produce nanostructured metals and alloys that have a combination of high strength and high ductility by tailoring microstructures of metal and alloys through SPD techniques. The extraordinary high ductility shown in ECAP-processed copper and HPT-processed Ti were rendered by new deformation mechanisms that do not operate in their coarse-grained counterpart. 
Nanostructured metals produced by SPD techniques have unique nanostructures. Because they are formed by plastic deformation, these nanostructures have many features related to deformation, including high dislocation densities, high- and low-angle grain boundaries in equilibrium or non-equilibrium states, subgrains with DDW as boundaries, and dislocation cells. The grains can be equiaxed, with size distributions following a lognormal function. These structural features are different from nanostructured materials synthesized by other techniques.

Not surprisingly, unique nanostructures, i.e. ultrafine grain size with high defect density, may have activated deformation mechanisms that yielded high ductility. It is not clear what are the deformation mechanisms and what nanostructures have enabled these deformation mechanisms. Further studies are needed to investigate these issues so that the nanostructures can be tailored through SPD techniques to obtain both high strength and high ductility in nanostructured metals and alloys.

\section{Acknowledgement}

This work is supported by the DOE NIS-IPP propram.

\section{References}

1. E.L. Hu and D.T. Shaw, Synthesis and Assembly, in Nanostructure Science and Technology, A Worldwide Study. Edited by R.W. Siegel, E. Hu, and M.C. Roco, Final Report by WTEC Panel p. 15 (1999).

2. H. Gleiter, in Deformation of Polycrystals: Mechanisms and Microstructures. Edited by Hansen et al, Roskilde, Denmark, Risø National Laboratory, p. 15 (1981).

3. G.W. Nieman, J.R. Weertman and R.W. Siegel, Scr. Metall., 23 (1989) 2013.

4. S.R. Agnew, B.R. Elliott, C.J. Yongdahl, K.J. Hemker and J.R. Weertman, Mater. Sci. Eng. A285 (2000) 391.

5. P.G. Sanders, J.A. Eastman, and J.R. Weertman, Acta. Mat. 45 (1997) 4019.

6. J. Rawer, G. Slavens, D. Govier, C. Dogan, and R. Doan, Metall. Mater. Trans. A 27 (1996) 3126.

7. G.R. Shaik and W.W. Milligan, Metall. Mater. Trans. A 28 (1997) 895.

8. L.He and E. Ma, J. Mater. Res. 11 (1996) 72.

8. R.S. Mishra, J.A. Schneider, J.F. Shackelford, and A.K. Mukherjee, Nanostr. Mat. 5 (1995) 525.

9. R.Z. Valiev, R.K. Islamgaliev and I.V. Alexandrov, Progress in Materials Science 45 (2000) 103.

10. V.M. Segal, Mater. Sci. Eng. A271 (1999) 322.

11. R.Z. Valiev, O.A. Kaibyshev, R.I. Kuznetsov, R.Sh. Musalimov and N.K. Tsenev, Dan. SSSR 301 (1988) 864.

12. A.K. Ghosh and W. Huang, Investigations and Applications of Severe Plastic Deformation (edited by T.C. Lowe and R.Z. Valiev), NATO Science Series, Series 3, High Technology, vol. 80, p. 29. Kluwer Academic Publications, Boston (2000).

13. W.D. Chen, D. Ferguson and H. Ferguson, Ultrafine Grained Materials (edited by R.S. Mishra, S.L. Semiatin, C. Suryanrayana, N.N. Thadhani, and T.C. Lowe), TMS, Warrendale, PA, p.235 (2000).

14. Y.T. Zhu, H. Jiang, J. Huang and T.C. Lowe, Metall. and Mater. Trans. A. 32 (2001) 1559.

15. E. Schmid and W. Boas, Plasticity of Crystals, with Special Reference to Metals (Chapman and Hall, London, 1968).

16. P.W. Bridgman, Studies in Large Plastic Flow and Fracture (McGraw-Hill, New York, 1952).

17. S.S. Hecker and M.G. Stout, in Deformation, Processing and Structure, G. Krauss ed. (ASM, Materials Park, OH, 1984), p37.

18. Z. Horita, T. Fujinami, M. Nemoto, and T.G. Langdon, Metall. Mater. Trans, 31A (2000) 691.

19. Y.T. Zhu and T.C. Lowe, Mater. Sci. Eng. A291 (2000) 46. 
20. R.Z. Valiev, I.V. Alexandrov, Y.T. Zhu and T.C. Lowe, "Paradox of strength and ductility in metals processed by severe plastic deformation," submitted to J. Mater. Res.

21. E.A. Brandes and G.B. Brook, Smithells Metals Reference Book, $7^{\text {th }}$ Edition, Ch. 22 (ButterworthHeinemann Ltd., Oxford, 1992)

22. E.R.Parker, Materials Data Book for Engineers and Scientists (McGraw-Hill Book Co., New York, 1967).

23. I.V. Alexandrov, Y.T. Zhu, T.C. Lowe, R.K. Islamgaliev and R.Z. Valiev, Metall. Mater. Trans. A, 29 (1998) 2253.

24. S. Ferrasse, V.M. Segal, K.T. Hartwig, and R.E Goforth, Metall. Mater. Trans. 28A (1997) 1047.

25. Y. Iwahashi, M. Furukawa, Z. Horita, M. Nemoto, and T.G. Langdon, Metall. Mater. Trans., 29A (1998) 2245.

26. D.H. Shin, B.C. Kim, K.T. Park, and W.Y. Choo, Acta Mater. 48 (2000) 3245.

27. J. Huang, Y.T. Zhu, H. Jiang, and T.C. Lowe, Acta Mater. 49 (2001) 1497.

28. N. Hansen, Mater. Sci. Tech. 6 (1990) 1039.

29. K. Oh-ishi, Z. Horita, D.J. Smith, and T.G. Langdon, J. Mater. Res. 16 (2000) 583.

30. Z. Horita, D.J. Smith, M. Furukawa, M. Nemoto, R.Z. Valiev, and T.G. Langdon, J. Mater. Res. 11 (1996) 1880.

31. Z. Horita, D.J. Smith, M. Nemoto, R.Z. Valiev, and T.G. Langdon, J. Mater. Res. 13, (1998) 446.

32. K. Oh-ishi, Z. Horita, D.J. Smith, M. Furukawa, R.Z. Valiev, M. Nemoto, and T.G. Langdon, J. Mater. Res. 14 (1999) 4200. 